\title{
PENGARUH TRANSFORMASI DATA PADA METODE LEARNING VECTOR QUANTIZATION TERHADAP AKURASI KLASIFIKASI DIAGNOSIS PENYAKIT JANTUNG
}

\author{
Arafa Rahman Aziz ${ }^{*}$, Budi Warsito ${ }^{2}$, Alan Prahutama ${ }^{3}$ \\ 1,2,3 Departemen Statistika, Fakultas Sains dan Matematika, Universitas Diponegoro \\ e-mail: arafa27aziz@students.undip.ac.id
}

\begin{abstract}
Learning Vector Quantization (LVQ) is a type of Artificial Neural Network with a supervised learning process based on competitive learning. Despite the absence of assumptions in LVQ is an advantage, it can be a problem when the predictor variables have big different ranges. This problems can be overcome by equalizing the range of all variables by data transformation so that all variables have relatively same effect. Heart Disease UC dataset which used in this study is transformed by several transformation methods, such as minmax, decimal scaling, z-score, mean-MAD, sigmoid, and softmax. The result show that the sixtransformed data can provide better LVQ classification accuracy than the raw data which has $75.99 \%$ for training performance accuracy. LVQ classification accuracy with data transformation of minmax, decimal scaling, z-score, mean-MAD, sigmoid, and softmax are $89.16 \%, 88.22 \%, 89.7 \%, 90.1 \%, 88.17 \%$ and $92.18 \%$. Based on the One-way ANOVA test and DMRT post hoctest known that there are significant differences between the results of the classification with data transformations and raw data in 0,05 significant level of $\alpha$. It is also known that the best data transformation methods are softmax for training and sigmoid for testing.
\end{abstract}

Keywords: heart disease, neural network, learning vector quantization, classification, data transformation

\section{PENDAHULUAN}

Jaringan Syaraf Tiruan (JST) adalah suatu sistem yang memiliki kemiripan dengan jaringan syaraf makhluk hidup dalam memproses informasi. Obyek pengamatan dalam JST dikenali dengan melakukan suatu pelatihan yang terstruktur dan terus menerus sampai sistem jaringan tersebut mampu mengenali obyek tersebut. JST dapat diterapkan untuk menyelesaikan permasalahan klasifikasi tanpa adanya berbagai asumsi klasik. Learning Vector Quantization (LVQ) merupakan salah satu jenis JST dengan proses pembelajaran terawasi yang berbasis competitive learning dimana hanya neuron pemenang saja yang diperhatikan. Neuron pemenang ditentukan dengan menghitung jarak euclid yang paling kecil antara vektor masukan dengan bobot neuron.

Permasalahan muncul ketika variabel-variabel prediktor memiliki jangkauan data yang saling berbeda dengan perbedaan yang cukup besar. Jangkauan yang besar memungkinkan variabel tersebut memiliki selisih yang besar pada perhitungan jarak euclid yang berakibat variabel dengan jangkauan kecil kehilangan pengaruh dalam menentukan hasil klasifikasi. Solusi permasalahan ini yaitu dengan menyamakan atau mendekatkan jangkauan antar variabel sehingga menjadi relatif sama dimana data ditransformasikan dengan cara tertentu. Proses ini dilakukan sebelum proses pengolahan data.

Penelitian klasifikasi dengan metode LVQ untuk data Heart Disease UCI dengan variabel 10 pilihan oleh Hidayati (2012) dilakukan tanpa melakukan transformasi data terlebih dahulu menghasilkan akurasi pelatihan 66,79\% [5]. Data Heart Disease UCI tersebut terdiri dari variabel kategorik dan numerik. Varibel numerik yang digunakan terdiri dari faktor usia, tingkat kolesterol, tekanan darah yang mana memiliki jangkauan yang saling berbeda. Sehingga peneliti menduga bahwa tidak maksimalnya akurasi tersebut karena adanya perbedaan jangkauan data yang cukup besar. 
Penelitian mengenai pengaruh transformasi data terhadap akurasi klasifikasi neural network pernah dilakukan oleh Chamidah et al (2012) dan Easa dan Arabo (2017) menggunakan model Backpropagation. Beberapa macam transformasi data yang berbeda diuji pada kedua penelitian tersebut seperti minmax, decimal scaling, z-score, mean-MAD, median-MAD, softmax, statistical column, dan norm transformation. Pada penelitian Chamidah et al (2012) metode minmax menjadi metode paling baik sedangkan pada penelitian Easa dan Arabo (2017) metode metode Mean-MAD menjadi metode terbaik diantara beberapa metode lain setelah diuji dengan beberapa dataset dari UCI.

Pada penelitian ini dilakukan klasifikasi dengan metode LVQ menggunakan enam metode transformasi data yang sesuai dengan kebutuhan klasifikasi yaitu minmax, decimal scaling, z-score, mean-MAD, sigmoid, dan softmax termasuk juga klasifikasi dengan data asli. Adapun data yang digunakan adalah data Heart Disease UCI dengan 13 variabel prediktor. Penelitian ini bertujuan untuk mengetahui pengaruh transformasi data terhadap akurasi klasifikasi data Heart Disease UCI baik pada proses pelatihan maupun pengujian.

\section{TINJAUAN PUSTAKA}

\subsection{Penyakit Jantung Koroner}

Istilah penyakit jantung (heart disease) sering digunakan untuk menerangkan sebuah penyakit pembuluh darah jantung [8]. Pembuluh darah tersebut disebut arteri koroner yang berfungsi untuk menyuplai oksigen dan berbagai zat gizi untuk otot jantung. Gangguan pada pembuluh darah ini biasa disebut dengan Penyakit Jantung Koroner (PJK) atau sering disebut juga penyakit arteri koroner (Coronary Artery Disease). Gangguan ini disebabkan oleh penumpukan kolesterol dan bahan lainnya yang disebut plak di dinding bagian dalam arteri yang mengakibatkan berkurangnya aliran darah melalui arteri. Dampaknya otot jantung tidak bisa mendapatkan darah atau oksigen yang sesuai kebutuhan.

\subsection{Pre-Processing}

Pre-Processing adalah langkah-langkah yang dilakukan sebelum tahap pelatihan, agar data sesuai dengan metode analisis yang digunakan. Salah satu tahap pre-processing adalah mengestimasi data yang hilang. Data yang hilang secara sederhana dapat diestimasi menggunakan nilai rata-rata atau median untuk data bilangan riil, dan nilai modus untuk data bilangan bulat.

Tahapan pre-processing berikutnya adalah transformasi data. Data yang memiliki beberapa variabel dengan jangkauan nilai yang berbeda-beda mengakibatkan variabel dengan nilai atau jangkauan yang besar mempunyai pengaruh yang lebih kuat dalam fungsi biaya daripada variabel dengan nilai atau jangkauan yang kecil [9]. Permasalahan ini dapat diatasi dengan dilakukan penyekalaan ulang terhadap data agar dimiliki jangkauan yang serupa pada semua variabel. Hal ini berlaku untuk permasalahan klasifikasi. Adapun metode transformasi yang digunakan antara lain:

- Minmax

Metode ini metode ini mengganti data dari suatu jangkauan ke jangkauan baru yang lain dengan tetap menjaga hubungan data yang asli [10]. Metode ini umumnya digunakan untuk menskalakan ulang data pada jangkauan 0 s.d. 1 sehingga rumusnya menjadi:

$$
x_{i}^{\prime}=\frac{x_{i}-\min \left(x_{i}\right)}{\max \left(x_{i}\right)-\min \left(x_{i}\right)}
$$


- Decimal Scaling

Metode decimal scaling bekerja dengan cara menggeser titik desimal pada nilai data. Banyaknya penggeseran titik desimal bergantung pada nilai maksimum absolut dari masing-masing fitur data atau variabel [10]. Rumus transformasi decimal scaling dengan $\mathrm{j}$ adalah nilai terkecil sedemikian sehingga nilai $\max \left(\left|x^{\prime}{ }_{i}\right|\right)<1$ sebagai berikut:

$$
x^{\prime}{ }_{i}=\frac{x_{i}}{10^{j}}
$$

- Z-Score

Z-score atau disebut juga skor baku adalah angka yang menunjukkan seberapa jauh skor mentah dari skor rata-rata $(\mu)$ dalam satuan simpangan baku $(\sigma)$. [12]. Metode ini mampu mereduksi pengaruh outlier terhadap sebaran data hasil transformasi. Adapun rumusnya sebagai berikut:

$$
x^{\prime}=\frac{x-\mu}{\sigma}
$$

- Mean-MAD

Metode ini mirip dengan metode z-score hanya saja nilai simpangan baku diganti dengan nilai Mean Absolute Deviation. Adapun rumusnya sebagai berikut [3]:

$$
x_{i}^{\prime}=\frac{x_{i}-\operatorname{mean}(x)}{M A D}
$$

Adapun nilai MAD ditentukan dengan:

$$
M A D=\frac{1}{n} \sum_{i=1}^{10}\left|x_{i}-\operatorname{mean}(x)\right|
$$

- $\quad$ Sigmoid

Fungsi sigmoid merupakan fungsi yang sering digunakan dalam transformasi data sebagai fungsi aktivasi dalam JST dimana ia merubah data menjadi bernilai minimal 0 dan maksimal 1. Rumus fungsi sigmoid yang digunakan sebagai berikut [2]:

$$
f(x)=\frac{1}{1+e^{-x}} \quad \text { untuk }-\infty<x<\infty
$$

- Softmax

Metode softmax mentransformasi data menggunakan fungsi sigmoid dengan memanfaatkan nilai skor baku sebagai input-nya. Adapun rumusnya sebagai berikut [2]

$$
\mathrm{x}^{\prime}=\frac{1}{1+e^{-\frac{x-\mu}{\sigma}}}
$$

\subsection{Learning Vector Quantization}

Learning Vector Quantization (LVQ) adalah suatu metode untuk melakukan pelatihan terhadap lapisan-lapisan kompetitif yang terawasi. Lapisan kompetitif akan belajar secara otomatis untuk melakukan klasifikasi terhadap vektor input yang diberikan. Apabila vektor input memiliki jarak yang sangat berdekatan, maka vektor-vektor tersebut dikelompokkan ke dalam kelas yang sama [15].

LVQ merupakan salah satu jenis ANN yang berbasis competitive learning, dimana dari nilai keluaran yang diberikan neuron dalam layer keluaran hanya neuron pemenang 
(neuron yang memiliki nilai terkecil) saja yang diperhatikan. Neuron tersebut akan mengalami pembaharuan bobot. Pembaharuan bobot pada neuron pemenang bisa dilakukan dengan penambahan maupun pengurangan [9].

Parameter-parameter yang digunakan dalam LVQ yang pertama adalah laju pembelajaran (Learning Rate) yang disimbolkan dengan $\alpha$ (alfa) memiliki nilai $0>\alpha>1$. Jika nilai $\alpha$ terlalu besar maka nilainya menjadi tidak stabil, tetapi jika terlalu kecil akan membuat proses pembelajaran menjadi lebih lama. Parameter yang kedua adalah Decrease of Alfa (Dec $\alpha$ ) yaitu penurunan laju pembelajaran. Nilai laju pembelajaran akan terus diturunkan setiap kali kenaikan iterasi dengan mengalikannya dengan Dec $\alpha$

Algoritma klasifikasi LVQ dipaparkan sebagai berikut:

1. Menentukan bobot awal, jumlah neuron, laju pembelajaran $(\alpha)$, dan jumlah epoch maksimal. Bobot awal dicari dengan memberikan nilai tengah dari jangkauan dari nilai setiap fitur.

2. Hitung kuantitasi atau jarak vektor (d) ke semua neuron manggunakan rumus

$$
d_{i}=\sqrt{\sum_{i=1}^{r}\left(\boldsymbol{x}_{\boldsymbol{i}}-\boldsymbol{w}_{\boldsymbol{i}}\right)^{2}}
$$

Neuron dengan kuantisasi terkecil dipilih untuk dijadikan pemenang.

3. Perbaharui bobot neuron pemenang menggunakan rumus

$$
w_{i}(\text { baru })= \begin{cases}\boldsymbol{w}_{\boldsymbol{i}}(\text { lama })+\alpha\left(\boldsymbol{x}_{\boldsymbol{i}}-\boldsymbol{w}_{\boldsymbol{i}}(\operatorname{lama})\right), & \text { jika } \omega_{w j}=\omega_{x} \\ w_{i}(\operatorname{lama})-\alpha\left(\boldsymbol{x}_{\boldsymbol{i}}-\boldsymbol{w}_{\boldsymbol{i}}(\operatorname{lam} a)\right), & \text { jika } \omega_{w j} \neq \omega_{x}\end{cases}
$$

4. Kembali ke langkah 2 hingga semua vektor memiliki kelas.

5. Perbaharui laju pembelajaran $(\alpha)$ dengan rumus

$$
\alpha_{\text {baru }}=(\operatorname{Dec} \alpha) \times \alpha_{\text {lama }}
$$

6. Uji kondisi berhenti ! Kondisi berhenti ditentukan dengan dicapainya nilai toleransi kesalahan (error) atau jika telah mencapai epoch maksimal. Jika kondisi belum terpenuhi ulangi langkah 2.

\subsection{Pengukuran Ketepatan Klasifikasi}

Pengukuran kinerja dalam klasifikasi dapat dilihat berdasarkan nilai Apparent Error Rate (APER). APER didefinisikan sebagai hasil observasi pada proses pelatihan yang mengalami kesalahan klasifikasi oleh fungsi klasifikasi [6]. Nilai APER dapat dicari dengan melihat hasil klasifikasi yang disajikan oleh matriks konfusi.

Tabel 1. Matriks Konfusi

\begin{tabular}{|l|l|l|}
\hline \multirow{2}{*}{$\begin{array}{c}\text { Kelas Asli Hasil } \\
\text { Observasi (i) }\end{array}$} & \multicolumn{2}{|c|}{ Kelas Hasil Prediksi (j) } \\
\cline { 2 - 3 } & Kelas $=1$ & Kelas $=2$ \\
\hline Kelas $=1$ & True Positive & False Positive \\
\hline Kelas $=2$ & False Negative & True Negative \\
\hline
\end{tabular}

Nilai APER dan akurasi dihitung menggunakan rumus:

$$
\begin{aligned}
& A P E R=\frac{F P+F N}{T P+T N+F P+F N} \\
& \text { Akurasi }=(1-A P E R) \times 100 \%
\end{aligned}
$$




\subsection{Validasi Data}

Metode K-Fold Cross Validation bekerja dengan menggunakan pendekatan bahwa setiap data digunakan dalam jumlah yang sama untuk pelatihan dan tepat satu kali untuk pengujian [9]. Ilustrasi validasi K Fold dengan tiga kali percobaan ditunjukan oleh Gambar 1.

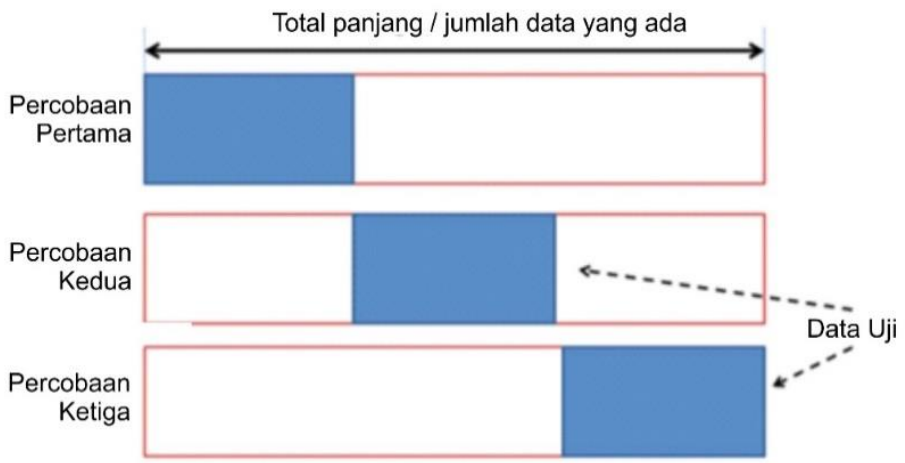

Gambar 1. Ilustrasi pembagian data pada evaluasi metode $K$-Fold Cross Validation

\subsection{ANOVA Satu Arah}

Uji ANOVA (Analisys of Varian) satu arah pada penelitian ini bertujuan untuk mengetahui apakah perlakuan atau faktor yang diberikan dari suatu percobaan memberikan perbedaan yang nyata (signifikan). Adapun penyebutan satu arah dikarenakan hanya satu faktor (yaitu perlakuan) yang diselidiki [16]. Pengambilan kesimpulannya didasarkan pada nilai $F_{\text {hitung }}$ yang dibandingkan dengan nilai $F_{\text {tabel }}$ yang terdapat pada tabel ANOVA dimana nilai $F_{\text {tabel }}$ diperoleh dari tabel distribusi $F$. Jika nantinya $\mathrm{H} 0$ ditolak atau $\mathrm{H} 1$ diterima maka selanjutnya dapat dilakukan uji pembandingan berganda (uji lanjut). Uji lanjut digunakan untuk menentukan perlakuan mana yang menyebabkan $\mathrm{H} 0$ ditolak yang salah satunya adalah uji Duncan Multiple Range Test (DMRT).

Tabel 2. ANOVA Satu Arah

\begin{tabular}{|c|c|c|c|c|c|}
\hline $\begin{array}{c}\text { Sumber } \\
\text { Keragaman }\end{array}$ & $\begin{array}{c}\text { Derajat } \\
\text { Bebas }\end{array}$ & $\begin{array}{c}\text { Jumlah } \\
\text { Kuadrat }\end{array}$ & $\begin{array}{l}\text { Kuadrat } \\
\text { Tengah }\end{array}$ & $F_{\text {hitung }}$ & $\mathrm{F}_{\text {tabel }}$ \\
\hline Perlakuan & $a-1$ & JKP & $\overline{\mathrm{KTP}}$ & KTP/KTG & $\mathrm{F}_{\mathrm{a}-1 ; \mathrm{a}(\mathrm{n}-1)}(\alpha)$ \\
\hline Galat & $a(n-1)$ & JKG & KTG & & \\
\hline Total & a.n-1 & JKT & & & \\
\hline
\end{tabular}

\section{METODE PENELITIAN}

\subsection{Sumber Data}

Data yang digunakan dalam penelitian ini adalah data sekunder yang berasal dari lokasi Cleveland Clinic Foundation. Data dengan judul "Heart Disease UCI" diunduh pada tanggal 1 Februari 2020 diperoleh dari website ICS UCI ( https://archive.ics.uci.edu/m1/machine learning-databases/heart-disease/processed.cleveland.data ) dengan ukuran data 303.

\subsection{Variabel Penelitian}

Data yang akan dianalisis merupakan data HeartDisease UCI Claveland yang terdiri dari 14 variabel hasil reduksi dari 76 variabel. Data tersebut merupakan data diagnosis penyakit jantung dengan 13 variabel prediktor. Adapun variabel-variabel yang digunakan sebagai berikut: 
Tabel 3. Variabel Penelitian Heart Disease UCI Cleveland

\begin{tabular}{|c|c|c|}
\hline Variabel & Deskripsi & Keterangan \\
\hline$\overline{X_{1}}$ & Umur (age) & Numerik \\
\hline$X_{2}$ & Jenis kelamin $(s e x)$ & $\begin{array}{l}\text { 1: Laki-Laki } \\
0: \text { Perempuan }\end{array}$ \\
\hline$X_{3}$ & Tipe sakit dada (cp) & $\begin{array}{l}\text { 1: Typical angina } \\
\text { 2: Atypical angina } \\
\text { 3: Non-anginalpain } \\
\text { 4: Asymptomatic }\end{array}$ \\
\hline $\mathrm{X}_{4}$ & Tekanan darah sistol (trestbps) & Numerik \\
\hline $\mathrm{X}_{5}$ & Kadar kolesterol (chol) & Numerik \\
\hline $\mathrm{X}_{6}$ & Gula darah puasa (fbs) & $\begin{array}{l}0:<120 \mathrm{mg} / \mathrm{dl} \\
1:>120 \mathrm{mg} / \mathrm{dl} \\
0: \text { Normal }\end{array}$ \\
\hline $\mathrm{X}_{7}$ & Hasil elektrokardiografik saat istirahat (restecg) & $\begin{array}{l}\text { 1: Adanya kelainan } \\
\text { gelombang ST-T } \\
\text { 2: Hipertrofil ventrikel }\end{array}$ \\
\hline $\mathrm{X}_{8}$ & Maksimum denyut jantung yang dapat dicapai (thalac) & Numerik \\
\hline $\mathrm{X}_{9}$ & $\begin{array}{l}\text { Ada tidaknya sakit dada akibat latihan yang diberikan } \\
\text { (exang) }\end{array}$ & $\begin{array}{l}\text { 1: Ya } \\
\text { 0: Tidak }\end{array}$ \\
\hline $\mathrm{X}_{10}$ & $\begin{array}{l}\text { Puncak segmen ST yang diperoleh dari latihan relatif } \\
\text { terhadap istirahat (oldpeak) }\end{array}$ & Numerik \\
\hline $\mathrm{X}_{11}$ & Kemiringan segmen ST untuk latihan maksimal (slope) & $\begin{array}{l}\text { 1: Up sloping } \\
\text { 2: Horizontalsloping } \\
\text { 3: Down sloping }\end{array}$ \\
\hline $\mathrm{X}_{12}$ & Pembuluh darah utama yang diwarnai oleh fluroskopi (ca) & $\begin{array}{l}0,1,2,3 \\
1: \text { Normal }\end{array}$ \\
\hline $\mathrm{X}_{13}$ & Tipe kerusakan pembuluh darah (thal) & $\begin{array}{l}\text { 2: Cacat tetap } \\
\text { 3: Cacat reversible }\end{array}$ \\
\hline Y & Diagnosis Penyakit Jantung & $\begin{array}{l}\text { 1: High risk } \\
\text { 2: Low risk }\end{array}$ \\
\hline
\end{tabular}

\subsection{Tahapan Analisis}

Program komputer yang digunakan untuk mendukung proses penelitian ini adalah software Microsoft Excel 2013, Minitab 14, dan Matlab 2015a. Adapun langkah-langkah pengolahan data yang dilakukan sebagai berikut:

1. Menyiapkan data Heart Disease UCI Cleveland.

2. Melakukan proses pre-processing berupa estimasi data hilang menggunakan software Microsoft Excel 2013.

3. Membagi data menjadi dua bagian yaitu data latih dan data uji. Proporsi yang digunakan adalah 67:33 (202:101) dan 80:20 (240:63)

4. Melakukan pre-processing berupa transformasi untuk data latih menggunakan transformasi yang sudah ditentukan, yaitu: minmax, mean-MAD, z-score, decimal scaling, sigmoid, dan softmax menggunakan software Microsoft Excel 2013.

5. Melakukan transformasi untuk data uji dengan menyesuaikan parameter transformasi pada data latih.

6. Melakukan input data latih dan data uji tanpa transformasi pada software Mmatlab 2015a.

7. Menentukan jumlah neuron, dan parameter. Jumlah neuron yang akan diuji adalah 5, 15, dan 25. Parameter learning rate yang diujikan yaitu: 0,25; 0,125; dan 0,025. Sedangkan untuk parameter lainnya nilainya tetap yaitu maksimum epoch yang digunakan adalah 300, Dec alfa yang digunakan adalah 0,1, dan nilai Min alfa yang digunakan adalah 0,001 . 
8. Melakukan proses pelatihan dan pengujian metode Learning Vector Quantization. Ulangi hingga 10 kali dan catat tiap akurasi dan peforrma yang dihasilkan. Uji pula validasinya menggunakan K-Fold Validation.

9. Melakukan (langkah 8) minimal sekali menggunakan peforma terbaik sebagai kriteria pemberhentian iterasi pada syntax 'net.trainParam.goal' pada program Matlab 2015a agar didapat akurasi dan bobot terbaik. Cetak pula bobot akhir yang dihasilkan.

10. Pilih parameter jumlah neuron, learning rate, dan maximum epoch yang menghasilkan akurasi terbaik pada (langkah 8) sebagai input untuk proses LVQ dengan data tertransformasi.

11. Melakukan (langkah 8) menggunakan data tertransformasi pada (langkah 4) dan parameter pada (langkah 10).

12. Melakukan (langkah 9) untuk klasifikasi LVQ dengan data tertransformasi agar diperoleh hasil optimal.

13. Membandingkan rata-rata akurasi klasifikasi metode LVQ dengan data tanpa transformasi dengan semua data tertransformasi. Bandingkan juga akurasi terbaik yang dihasilkan.

14. Melakukan pengujian secara statistik untuk memperoleh kesimpulan yang objektif apakah penggunaan keenam metode transformasi memberikan pengaruh yang nyata menggunakan uji ANOVA Satu Arah dan uji lanjut DMRT.

\section{HASIL DAN PEMBAHASAN}

Data Heart Disease UCI terdiri dari 13 variabel prediktor. Dua diantaranya terdapat data hilang. Data hilang terdapat pada variabel $X_{12}$ sebanyak tiga dan $X_{13}$ sebanyak dua. Kedua variabel tersebut merupakan variabel dengan tipe kategorik sehingga penggantian nilai data hilang dilakukan menggunakan nilai modus pada masing-masing kelasnya.
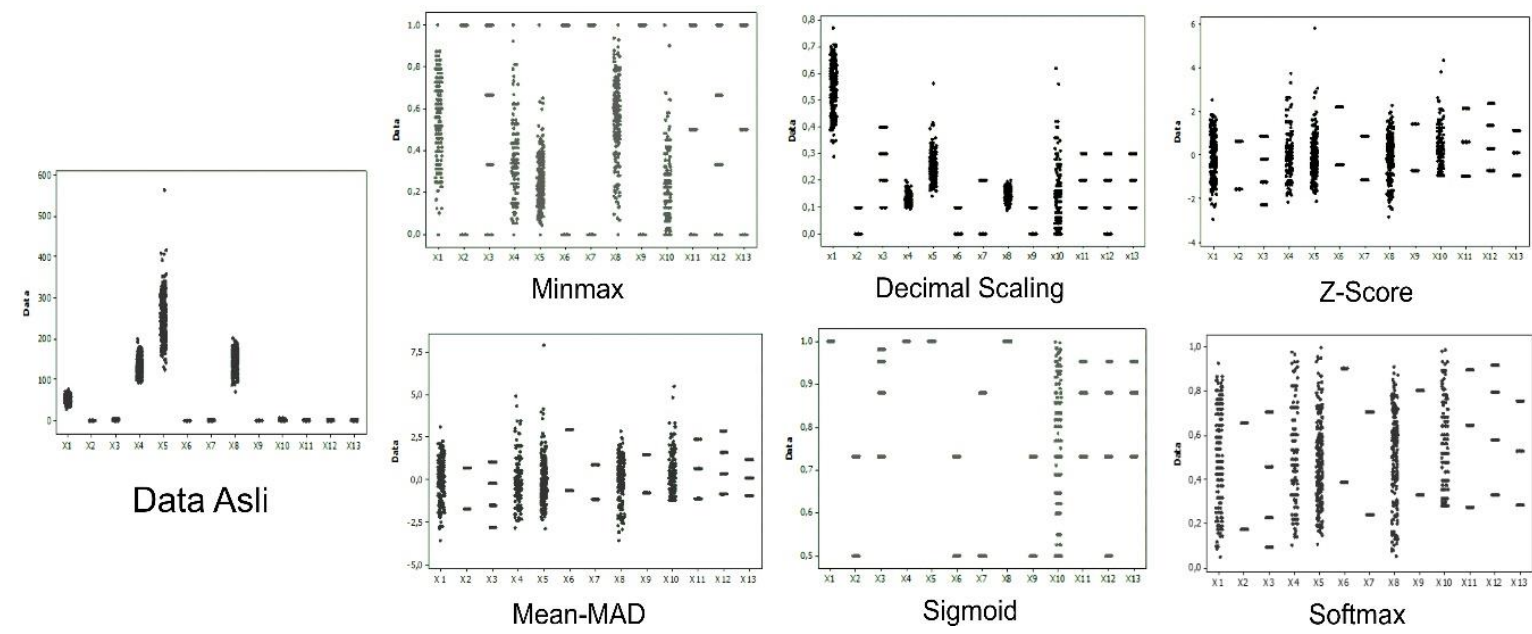

Gambar 2. Plot Data Heart Disease UCI

Berdasarkan Gambar 2 ditampakkan bahwa pada data asli persebaran data dari beberapa variabelnya tidak merata yang mengakibatkan hasil klasifikasi akan banyak dipengaruhi oleh variabel yang memiliki jangkauan paling besar yaitu variabel $\mathrm{X}_{5}$, diikuti variabel $\mathrm{X}_{4}$ dan $\mathrm{X}_{8}$. Pada data yang telah ditransformasi penyebaran data menjadi lebih merata meskipun tidak sempurna. Masing-masing transformasi memiliki penyebaran data yang berbeda. Pada transformasi minmax nilai minimal danmaskimal data benar-benar sama. Pada transformasi decimal scaling jangkauan data masih cukup merata meskipun nilainya berbeda. Pada transformasi z-score dan mean-MAD sebagian besar data berada 
pada jangkauan yang seimbang dengan tidak memaksakan outlier masuk kedalam jangkauan secara umumnya. Pada transformasi softmax data menyebar cukup merata.

Perhitungan pertama yang dilakukan adalah klasifikasi LVQ dengan data asli yang dilakukan sesuai dengan algoritma yang sudah dibahas sebelumnya. Hasilnya akurasi terbaik diperoleh pada proporsi data latih $67 \%$ : data uji $33 \%$, laju pembelajaran $\alpha=0,125$, dan jumlah neuron 25. Adapun akurasi terbaik yang diperoleh adalah 75,99\% untuk rata-rata pelatihan dari 10 kali percobaan dengan 61,78\% untuk rata-rata pengujian dan 80,22\% untuk akurasi pelatihan maksimal yang dapat dicapai.

Parameter terbaik yang sudah diperoleh kemudian diaplikasikan pada klasifikasi LVQ dengan transformasi data. Hasilnya diperoleh meotde transformasi yang mampu menghasilkan akurasi tertinggi untuk proses pelatihan yaitu softmax, sedangkan untuk proses pengujian akurasi tertinggi dihasilkan oleh metode sigmoid. Hasil selengkapnya dapat dilihat pada tabel berikut

Tabel 4. Perbandingan Akurasi Klasifikasi LVQ dengan Transformasi Data

\begin{tabular}{|c|c|c|c|c|c|c|c|}
\hline \multirow{2}{*}{ Jenis Data } & \multicolumn{2}{|c|}{ Nilai Rata-Rata (\%) } & \multirow{2}{*}{$\begin{array}{c}\text { Akurasi } \\
\text { Maksimum* (\%) }\end{array}$} & \multicolumn{4}{|c|}{ K-Fold Cross Validation (\%) } \\
\hline & Pelatihan & Pengujian & & F1 & F2 & F3 & $s$ \\
\hline Asli & 75,99 & 61,78 & 81,19 & $\begin{array}{r}75,59 \\
(60,5)\end{array}$ & $\begin{array}{l}77,77 \\
(63,66)\end{array}$ & $\begin{array}{l}75,99 \\
(61,78)\end{array}$ & $\begin{array}{l}0,95 \\
(1,3)\end{array}$ \\
\hline Minmax & 89,16 & 74,95 & 91,58 & $\begin{array}{l}87,03 \\
(78,71)\end{array}$ & $\begin{array}{r}86,98 \\
(79,7)\end{array}$ & $\begin{array}{l}89,16 \\
(74,95)\end{array}$ & $\begin{array}{r}1,02 \\
(2,05)\end{array}$ \\
\hline Dec. Scaling & 88,22 & 75,54 & 92,08 & $\begin{array}{l}86,83 \\
(82,48)\end{array}$ & $\begin{array}{r}87,92 \\
(80,5)\end{array}$ & $\begin{array}{l}88,21 \\
(75,54)\end{array}$ & $\begin{array}{r}0,6 \\
(2,91)\end{array}$ \\
\hline Z-Score & 89,70 & 77,13 & 93,07 & $\begin{array}{l}89,06 \\
(81,29)\end{array}$ & $\begin{array}{l}88,91 \\
(79,21)\end{array}$ & $\begin{array}{r}89,7 \\
(77,13)\end{array}$ & $\begin{array}{l}0,34 \\
(1,7)\end{array}$ \\
\hline Mean MAD & 90,10 & 78,42 & 94,06 & $\begin{array}{l}88,42 \\
(81,29)\end{array}$ & $\begin{array}{l}87,62 \\
(78,32)\end{array}$ & $\begin{array}{r}90,1 \\
(78,22)\end{array}$ & $\begin{array}{r}1,03 \\
(1,08)\end{array}$ \\
\hline Sigmoid & 88,17 & 81,09 & 92,08 & $\begin{array}{l}88,22 \\
(81,49)\end{array}$ & $\begin{array}{l}89,75 \\
(80,01)\end{array}$ & $\begin{array}{l}88,17 \\
(81,09)\end{array}$ & $\begin{array}{c}0,74 \\
(0,58)\end{array}$ \\
\hline Softmax & 92,18 & 76,63 & 96,04 & $\begin{array}{l}90,00 \\
(82,57)\end{array}$ & $\begin{array}{l}90,69 \\
(80,10)\end{array}$ & $\begin{array}{l}92,18 \\
(76,63)\end{array}$ & $\begin{array}{r}0,3 \\
(2,4)\end{array}$ \\
\hline
\end{tabular}

Catatan: *menunjukkan hasil akurasi klasifikasi dengan data pelatihan, tanda kurung "( )" menyatakan hasil pengujian

Berdasarkan Tabel 15 dapat diketahui bahwa terdapat perbedaan yang cukup jelas yaitu lebih dari $10 \%$ antara klasifikasi LVQ tanpa transformasi dengan klasifikasi LVQ dengan transformasi data baik pada proses pelatihan maupun pengujian. Pada percobaan yang diulang sepuluh kali didapat metode transformasi softmax mampu menghasilkan akurasi data pelatihan paling tinggi sebsesar 92,18\% dengan akurasi 76,63\% untuk proses pengujian. Metode transformasi data yang memberikan hasil terendah pada proses pelatihan adalah sigmoid dengan akurasi 88,17\% namun mampu memberikan hasil paling baik dalam proses pengujian dengan akurasi sebesar $81,09 \%$. Hasil validasi dengan K-Fold Cross Validation menunjukkan hasil yang cukup stabil karena nilai standar deviasi $(s)$ yang masih cukup kecil kurang dari 3.

Hasil rata-rata akurasi pada Tabel 2 dilakukan pengujian secara statistik dengan ANOVA Satu Arah untuk mengetahui apakah perbedaan akurasi tersebut signifikan. Adapun nilai $\alpha$ yang digunakan adalah 5\%. Perlakuannya adalah jenis transformasi data. 
Tabel 5. Tabel ANOVA Pelatihan dan Pengujian

\begin{tabular}{|c|l|r|r|r|r|r|}
\hline Data & \multicolumn{6}{|c|}{ Tabel ANOVA } \\
\hline \multirow{4}{*}{ Pelatihan } & Sumber Keragaman & Db & \multicolumn{1}{c|}{ JK } & KT & F Fitung & F $_{\text {tabel }}$ \\
\cline { 2 - 7 } & Transformasi Data & 6 & 1695,366 & 282,561 & 145,535 & 2,25 \\
& Galat & 63 & 122,317 & 1,942 & & \\
& Total & 69 & 1817,682 & & & \\
\hline \multirow{5}{*}{ Pengujian } & Sumber Keragaman & $\mathrm{Db}$ & $\mathrm{JK}$ & $\mathrm{KT}$ & Fhitung & $\mathrm{F}_{\text {tabel }}$ \\
\cline { 2 - 7 } & Transformasi Data & 6 & 2309,152 & 384,859 & 59,396 & 2,25 \\
& Galat & 63 & 408,213 & 6,48 & & \\
& Total & 69 & 2717,366 & & & \\
\hline
\end{tabular}

Tabel ANOVA di atas menunjukkan bahwa nilai $F_{\text {hitung }}>F_{\text {tabel }}$ baik pada hasil pelatihan maupun pengujian. Sehingga $\mathrm{H}_{0}$ ditolak dan dapat disimpulkan bahwa adanya pengaruh transformasi data terhadap akurasi klasifikasi LVQ dengan data Heart Disease UCI.

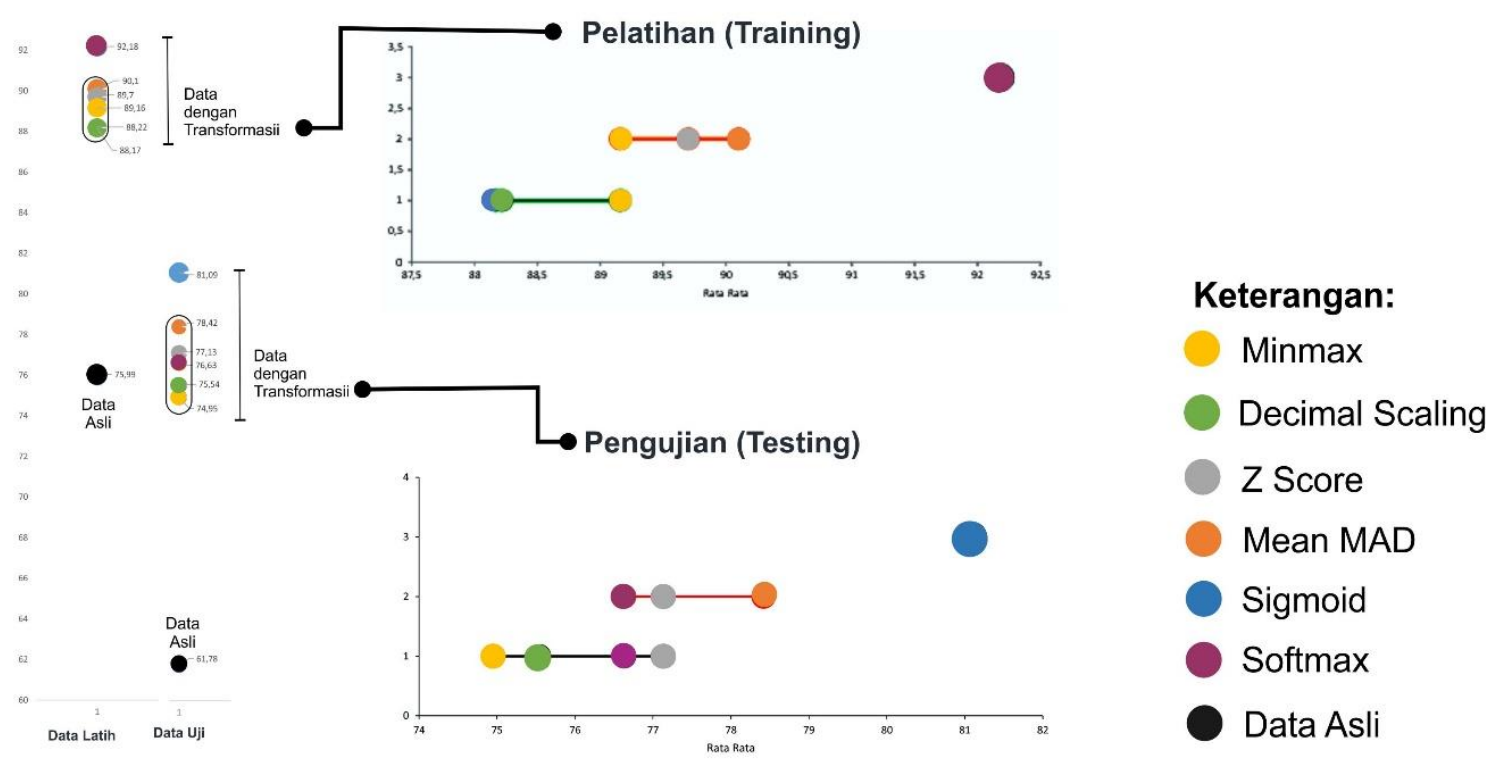

Gambar 3. Hasil Uji DMRT

Hasil uji lanjut menunjukkan bahwa keenam metode transformasi yang diujikan berbeda secara signifikan terhadap akurasi dengan data asli. Lebih lanjut diketahui bahwa metode transformasi data yang paling baik adalah softmax untuk pelatihan dan sigmoid untuk pengujian.

\section{KESIMPULAN}

Berdasarkan hasil dan pembahasan, dapat diperoleh kesimpulan sebagai berikut:

1. Hasil klasifikasi LVQ data Heart Disease UCI menggunakan enam metode transformasi yaitu minmax, decimal scaling, $\mathrm{z}$ score, mean MAD, sigmoid, dan $\mathrm{z}$ score, keseluruhannya lebih baik secara signifikan daripada klasifikasi dengan tanpa transformasi data baik pada pelatihan maupun pada pengujian berdasarkan uji ANOVA satu arah pada taraf signifikansi $\alpha=5 \%$ dengan nilai Fhitung $=145,535>$ Ftabel $=2,25$ untuk pelatihan dan nilai Fhitung $=59,396>$ Ftabel $=2,25$ untuk pengujian. 
2. Transformasi data yang menghasilkan akurasi klasifikasi LVQ data Heart Disease UCI terbaik berdasarkan uji lanjut DMRT adalah transformasi softmax untuk pelatihan dan transformasi sigmoid untuk pengujian.

\section{DAFTAR PUSTAKA}

[1] Berry, M. W., Mohammed, A., \& Yap, B.W. 2016. Soft Computing in Data Science. Singapura: Springer

[2] Chamidah, N., Winarto, \& Salamah, U. 2012. Pengaruh Normalisasi Data pada Jaringan SyarafTiruan Backpropagasi Gradient Descent Adaptive Gain (BPGDAG) untuk Klasifikasi. ITSMART, Vol 1, No 1: hlm 28-33

[3] Eesa, A., \& Arabo, W. 2017. A Normalization Methods for Backpropagation: A Comparative Study. Science Journal of University of Zakho Vol 5, No 4: hlm 319323

[4] Hendrawati, T. 2015. Kajian Metode Imputasi dalam Menangani Missing Data. Prosiding Seminar Nasional Matematika dan Pendidikan Matematika UMS 2015. No 67, hlm: 637-642

[5] Hidayati, N., \& Warsito, B. 2012. Prediksi Terjangkitnya Penyakit Jantung dengan Metode Learning Vector Quantization. Media Statistika, Vol. 3, No. 1: hlm 21-30

[6] Johnson, R. \& Wichern, D. 2007. Applied Multivariate Statistical Analysis. Edisi 6. USA: Pearson Education Inc

[7] Kusumadewi, S. 2004. Membangun Jaringan SyarafTiruan (Menggunakan Matlab dan Excel Link). Edisi 1. Yogyakarta: Graha Ilmu

[8] Lovastatin, K. 2006. Penyakit Jantung dan Penanganannya dengan Metode Alami. Diterjemahkan oleh: Slamet Rianto. Jakarta: PT. P restasi Pustakaraya. Terjemahan dari: Mayo Clinic On Heart Disease and High Blood Pressure

[9] Prasetyo, E. 2014. Data Mining - Mengolah Data menjadi Informasi Menggunakan Matlab. Yogyakarta: ANDI

[10] Pan, J., Zhuang, Y., \& Fong, S. 2016. The Impact of Data Normalization on Stock Market Prediction: Using SVM and Technical Indicators. CCIS, Vol 652, No 7: hlm $72-88$

[11] Siang, J. 2005. Jaringan Syaraf Tiruan dan Pemrogramannya Menggunakan Matlab. Yogyakarta: ANDI.

[12] Sufren, N. Y. 2013. Mahir Menggunakan SPSS Secara Otodidak. Jakarta: PT Elex Media Komputindo

[13] Soeharto, I. 2004. Penyakit Jantung Koroner dan Serangan Jantung . Jakarta: PT Gramedia Pustaka Utama

[14] [UCI] University of California Irvine. 1988. Heart Disease Dataset. https://archive.ics.uci.edu/ml/datasets/Heart+Disease. Diakses: 9 Februari 2020

[15] Warsito, B. 2009. Kapita Selekta Statistika Neural Network. Semarang: BP Undip Semarang.

[16] Widiharih, T. 2007. Buku Ajar Rancangan Percobaan. Semarang: Program Studi Statistika Jurusan Matematika Undip 